\title{
Training in peroral endoscopic myotomy (POEM) for esophageal achalasia
}

This article was published in the following Dove Press journal:

Therapeutics and Clinical Risk Management

5 July 2012

Number of times this article has been viewed

\section{Nicholas Eleftheriadis \\ Haruhiro Inoue \\ Haruo Ikeda \\ Manabu Onimaru \\ Akira Yoshida \\ Toshihisa Hosoya \\ Roberta Maselli \\ Shin-ei Kudo}

Digestive Disease Center, Showa University Northern Yokohama

Hospital, Yokohama, Japan

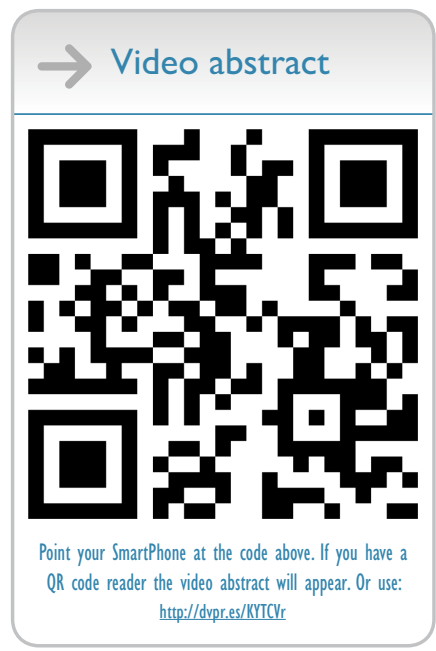

Correspondence: Nicholas Eleftheriadis Digestive Disease Center, Showa University, Northern Yokohama Hospital, 35-I Chigasakichuo, Tsuzuki-ku, Yokohama, 224-8503 Japan

Tel +8I 459497000

Email nikoseleftheriadis@yahoo.com
Abstract: Peroral endoscopic myotomy (POEM) has been developed in the context of natural orifice transluminal endoscopic surgery (NOTES) as a minimally invasive endoscopic treatment for symptomatic esophageal achalasia, which is a chronic progressive benign disease with severe morbidity and difficult management. Since September 2008, POEM has been successfully performed in more than 200 consecutive patients with symptomatic achalasia at the Digestive Disease Center of Showa University, Northern Yokohama Hospital, Yokohama, Japan, with excellent short- and long-term results and absence of serious complications. International experience of POEM within clinical studies is also promising. According to these results, POEM is considered as a safe procedure that can be applied to all achalasia patients. However, the low incidence of achalasia $(0.3 \%-1 \%$ per 100,000 population $)$, in combination with the potential serious complications related to the technically demanding POEM procedure, has made training difficult. There is therefore an urgent need for an animal model for training to decrease the learning curve. Further, there are other ethical and training issues to address. The pig is the most appropriate animal model for training in POEM due to its anatomy being similar to that of humans. The porcine esophagus has the advantage of easy mobilization due to absence of tight junctions to surrounding organs. A non-survival porcine model would be a simple, inexpensive, and reproducible animal model for training in POEM, without the need for concern about complications. A possible training process might first involve observation of POEM performed by specialists, then training on non-survival and survival porcine models, followed by training in humans under specialist guidance and finally, performance of POEM in humans.

Keywords: porcine organ model, non-survival, porcine esophagus, Heller myotomy

\section{Background}

Achalasia (the word itself a Greek term that means "does not relax"1) is a chronic benign disease with a subtle onset and symptoms that may progress gradually for years before exact diagnosis can be made. ${ }^{2,3}$ It is the most common primary motility disorder of the esophagus; however, it occurs rarely, with an annual incidence of approximately 0.03-1/100,000 per year. ${ }^{1,4}$ Achalasia affects men and women equally and may occur at any age, from children to octogenarians..$^{2,3,5}$

Despite increasing understanding of its pathophysiology, the etiology of achalasia remains largely unknown, ${ }^{6}$ while all current treatments have different advantages and drawbacks. ${ }^{7}$ Therapy has focused mainly on the forced relaxation of the lower esophageal sphincter (LES) by endoscopic or surgical means. ${ }^{7-17}$ As few randomized control trials have tried to determine the optimal strategy, treatment still varies widely. ${ }^{18,19}$ 
Pharmacologic treatment includes nitrate and calcium antagonists, with only temporary and unsatisfactory effects and often troublesome side effects. ${ }^{20,21}$ Noninvasive firstline endoscopic treatments are botulinum toxin ("Botox") injection and esophageal balloon dilatation. ${ }^{22,23}$ Botox provides inferior results and should be reserved for temporalizing therapy before radical procedure or patients who are poor candidates for surgery. ${ }^{10,21}$

Endoscopic pneumatic balloon dilatation temporarily relieves dysphagia in up to $70 \%$ of cases and is still widely performed because of its relative noninvasiveness. However, it is associated with a higher risk of esophageal perforation (2.5\%) and frequent recurrences; further, multiple treatments are often required and it has a lower success rate than surgery. ${ }^{10,12,13,15,21,24}$ The cumulative 5-year remission rate of pneumatic dilatation for achalasia is reported to be between $50 \%$ to $70 \%$. $^{10,24}$

If these interventions are ineffective, myotomy is generally indicated. ${ }^{21}$ Although surgical myotomy had provided an otherwise final solution for esophageal achalasia, the technique still has limitations and failures. In particular, gastroesophageal reflux disease (GERD) may occur in 30\% of cases ${ }^{24}$ after Heller myotomy, while failure is reported in $10 \%$ to $15 \% .{ }^{25}$ Heller myotomy should be accompanied by an additional antireflux procedure, such as Dor fundoplication. ${ }^{26,27}$ Ellis et al have reported limited esophageal myotomy without antireflux procedure in esophageal achalasia, however, long-term results were poor due to persistent disease in the esophageal body and late GERD. ${ }^{28}$

Laparoscopic esophagomyotomy is a less invasive technique that significantly reduces the morbidity of surgical therapy. However, it still requires several abdominal incisions and involves complete mobilization of the esophagogastric junction (EGJ), with subsequent requirement of antireflux operation. ${ }^{7,8}$ Reoperation after failure of laparoscopic myotomy often requires open surgery, ${ }^{25,29}$ which is a relatively difficult procedure, since adjacent structures of the distal esophagus are inevitably dissected.

In atypical or mixed cases of esophageal motility disorders, such as vigorous achalasia, diffuse esophageal spasm or nutcracker esophagus, classical surgical myotomy, which provides an approximately maximum $7-10 \mathrm{~cm}$ myotomy (an average 5-6 cm), often results in failure of complete symptom control. ${ }^{30}$

Recently, the concept of natural orifice transluminal endoscopic surgery (NOTES) $)^{31-33}$ has inspired endoscopists and endoscopic surgeons to create and establish novel, less invasive treatments for various gastrointestinal (GI) diseases.
Peroral endoscopic myotomy (POEM) has been developed in the context of NOTES as an incisionless, minimally invasive endoscopic treatment as a permanent cure for esophageal achalasia. $^{34}$

\section{Historical perspectives of POEM}

The concept of endoscopic myotomy for treatment of achalasia was first reported in a case series in $1980 .{ }^{19}$ However, the direct incision method through the mucosal layer was not considered a safe and reliable approach and this method has not been further pursued.

Pasricha and colleagues ${ }^{35}$ recently reported the possibility of endoscopic myotomy through a submucosal tunnel in a porcine model, which enabled the closure of the mucosalsubmucosal opening away from the myotomy site. Sumiyama and colleagues ${ }^{36}$ also reported the technical usefulness of submucosal tunneling in a porcine model, while Perretta et $\mathrm{al}^{37}$ have reported the safety and feasibility of endoscopic submucosal esophageal myotomy in a pig model.

Based on these experimental data, Inoue and colleagues ${ }^{34,41}$ developed a novel method of endoscopic myotomy established for application in humans with achalasia ${ }^{38,39}$ and other spastic esophageal motility disorders. ${ }^{40}$ Inoue et al coined the term "POEM" (peroral endoscopic myotomy) and initially reported favorable results in 17 achalasia patients. ${ }^{39}$ The procedure and its indications are described following.

\section{The POEM procedure} Indications for POEM

All patients with symptomatic achalasia can be treated by POEM. In the authors' early study, the indication for POEM was limited to non-sigmoid-type achalasia. Recently, however, the authors have been performing POEM for sigmoid-type achalasia. ${ }^{39}$ Sigmoid type is subdivided into sigmoid type 1 (S1) and sigmoid type 2 (S2) according to radiological signs on computed tomography (CT): in $\mathrm{S} 1$, the esophagus is significantly dilated and tortuous but only a single lumen is seen on CT; in S2, the esophagus is very dilated and severely tortuous with U-turns in a proximal direction and a double lumen is identified on some CT slices. In S1 achalasia, the esophageal lumen is tortuous but the direction is still downward. S2 type is an extremely advanced sigmoid form, where the esophageal lumen is tortuous and turns upward..$^{38,39}$ It is reported that simple myotomy will not relieve symptoms in S2-type achalasia and straightening of curved esophagus is recommended in addition to laparoscopic myotomy. ${ }^{38,39}$ However, based on the authors' results, POEM is useful in all grades of achalasia. 
Further, previous therapy, such as uncomplicated balloon dilation, is not a contraindication for POEM, although in these cases submucosal dissection at the EGJ may be difficult due to potential inflammatory fibrosis.

According to authors' unpublished data from POEM procedures, performed in the Digestive Disease Center of Showa University, Northern Yokohama Hospital and in contrast to the traditional belief, the circular muscle layer at the EGJ responsible for achalasia is relatively thinner than the circular muscle layer at the esophageal body. This makes complete myotomy at the EGJ even more difficult. Recently the indication for POEM was extended to failed surgical myotomy cases or failed previous POEM procedures, according to authors' unpublished data from Digestive Disease Center of Showa University, Northern Yokohama Hospital, Japan. Currently, the authors make no exceptions when considering the application of POEM.

\section{Evaluation before and after POEM Dysphagia symptom score}

To evaluate the treatment response to POEM, there are different validating scoring systems. ${ }^{11,30}$ A multitude of symptoms have been queried, with dysphagia the main symptom in all studies. Eckardt ${ }^{42}$ and Vaezi et $\mathrm{a}^{43}$ clinical scores were used in the authors' studies. ${ }^{39}$ Eckardt clinical score $^{42}$ is the sum of symptom scores for dysphagia, regurgitation and chest pain with: 0 indicating the absence of symptoms, 1 indicating occasional symptoms, 2 indicating daily symptoms and 3 indicating symptoms at each meal. In terms of weight-loss scoring, 0 indicates no weight loss, 1 indicates a loss of $<5 \mathrm{~kg}, 2$ indicates a loss of 5 to $10 \mathrm{~kg}$ and 3 indicates a loss of $>10 \mathrm{~kg}$. Thus, the maximum score on the Eckardt scale, ${ }^{44}$ indicating the most pronounced symptoms, is 12 (Table 1).

According to the Vaezi et $\mathrm{al}^{43}$ scoring system, the total symptom score consists of the sum of scores for dysphagia, regurgitation and chest pain (Table 2). The frequency of each symptom is graded on a scale ranging from 0 to 5 , where: $0=$ none, $1=$ once per month or less, $2=$ once per week,

Table I Eckardt's ${ }^{42}$ grading system for evaluation of clinical symptom severity for achalasia (total maximum score is 12)

\begin{tabular}{lllll}
\hline Symptom & Each meal & Daily & Weekly & None \\
\hline Dysphagia & 3 & 2 & $\mathrm{I}$ & 0 \\
Regurgitation & 3 & 2 & $\mathrm{I}$ & 0 \\
Chest pain & 3 & 2 & $\mathrm{I}$ & 0 \\
Weight loss & $>10 \mathbf{~ k g}$ & $\mathbf{5}-1 \mathbf{0 ~} \mathbf{~ k g}$ & $<\mathbf{5} \mathbf{~ k g}$ & No weight loss \\
Score & 3 & 3 & $\mathrm{I}$ & 0 \\
\hline
\end{tabular}

up to 3-4 times a month, 3=2-4 times per week, $4=$ once per day and $5=$ several times per day. The maximum score according to the Vaezi et al ${ }^{43}$ symptom scoring system is therefore 15 .

\section{Upper digestive endoscopy}

Esophagogastroscopy is performed before and the day after POEM. Preoperatively, gastroscopy is of significance not only in excluding malignancy or other simultaneous anatomic variations, but also in revealing esophageal dilatation or tortuosity, identifying potential simultaneous contractions and assessing the individual esophageal anatomy. It is also useful in assessing the residual esophageal content and carefully cleaning the esophageal lumen before POEM.

Particularly, the upper and lower esophageal sphincter can be thoroughly evaluated; compressions from spine, aortic arch and left main bronchus can be identified; LES zone and the presence of simultaneous contractions are recognized; the possible length of myotomy is determined; and the possible place of initial submucosal entry just lower to the level of left main bronchus compression is assessed.

The endoscopic evaluation of EGJ tightness is of interest, especially the subjective feeling of resistance, while passing the endoscope through the high LES zone and the subjective LES opening after air insufflation or in retroversion. Smooth passage of the endoscope via EGJ and obvious opening of EGJ in retroversion view during POEM are good indicators for adequate myotomy. The ability to control the efficacy of myotomy during the procedure and to further expand it until complete myotomy is achieved is one of the major advantages of POEM.

The day following POEM, endoscopy is necessary to confirm mucosal integrity and to evaluate the efficacy of myotomy. It should be reinforced that after complete myotomy, the mucosal layer is the only barrier between the esophageal lumen and the mediastinum.

\section{Barium swallow and CT scan}

Before POEM is performed, all patients undergo a barium swallow and an abdominal CT scan. These examinations are important in all cases before POEM.

A barium esophagogram may reveal three different types of distal esophageal morphology (Morphological classification of achalasia is reported in Omura et $\mathrm{al}^{45}$ ) (Figure 1): spindle, flask, or sigmoid. Moreover, the degree of esophageal dilatation is determined and classified according to the maximum diameter of the esophageal lumen into three grades: Grade I, $<3.5 \mathrm{~cm}$; Grade II, $3.5-6 \mathrm{~cm}$; and 
Table 2 Vaezi et al's ${ }^{43}$ grading system for evaluation of symptom severity for achalasia (total maximum score is 15 )

\begin{tabular}{lllllll}
\hline Symptom & None & $\begin{array}{l}\text { Once per } \\
\text { month }\end{array}$ & $\begin{array}{l}\text { Once per } \\
\text { week }\end{array}$ & $\begin{array}{l}\text { 2-4 times } \\
\text { per week }\end{array}$ & $\begin{array}{l}\text { Once per } \\
\text { day }\end{array}$ & $\begin{array}{l}\text { Several times } \\
\text { per day }\end{array}$ \\
\hline Dysphagia & 0 & $\mathrm{I}$ & 2 & 3 & 4 & 5 \\
Regurgitation & 0 & 1 & 2 & 3 & 4 & 5 \\
Chest pain & 0 & $\mathrm{I}$ & 2 & 3 & 4 & 5 \\
\hline
\end{tabular}

Grade III, $>6 \mathrm{~cm}$. The comparison of the maximum dilation esophageal diameter in barium esophagograms before and the day after POEM is important for objective evaluation of therapy. Video recording the barium swallow is a good approach for allowing the observation of physiological esophageal motility in real time.

The CT scan (chest-abdomen-pelvis) provides information not only about the degree of esophageal dilatation but also about the anatomical features of adjacent structures. Particularly, the CT scan is important in diagnosing concomitant congenital anomalies, such as duplicate esophagus, abnormally large vessels and ectopic varices and is significant in differentiating sigmoid- from non-sigmoid-type achalasia and the sigmoid subtypes.

On the day following POEM, thoracic X-ray and/or CT scan should be performed, upon indication, to exclude emphysema. Esophagogram is also performed the day following POEM to confirm smooth passage of contrast media through the EGJ and to exclude leakage or stasis (Figures 2-4). Moreover, the maximum esophageal dilation is compared with that before POEM. In this way, any possible complication is excluded, while efficacy of therapy is evaluated by viewing the video recording of the esophageal motility.

\section{Esophageal manometry}

Esophageal manometry has been traditionally considered the examination of choice for diagnosis of achalasia and has

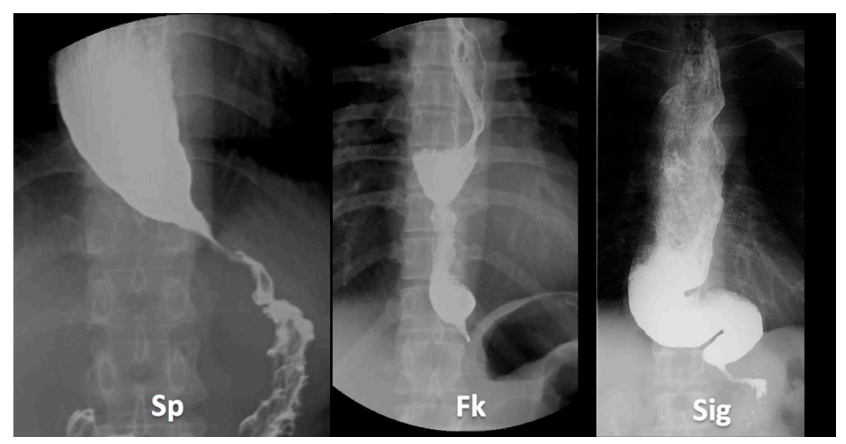

Figure I Classification of distal esophageal morphology in esophageal achalasia. Note: Cases from Showa University Northern Yokohama Hospital, Yokohama, Japan. Abbreviations: Sp, spindle type; Fk, flask type; Sig, sigmoid type. played a central role in research and clinical practice. The conventional diagnostic manometric criteria for achalasia are: elevated resting LES pressure, incomplete LES relaxation after swallow and absence of normally propagated peristaltic contraction. ${ }^{1,46,47}$ Another important manometric finding of clinical significance is the presence or absence of simultaneous esophageal contractions.

Classical-type achalasia (Figure 2) shows absence of motility (aperistalsis), while the presence of spontaneously simultaneous contractions is found in mixed or atypical cases, such as vigorous achalasia (Figure 3) (with high amplitude $>$ $60 \mathrm{mmHg}$ ) or diffuse esophageal spasm and may correspond to coexisting chest pain. In these latter cases, longer myotomy is especially beneficial.

Esophageal manometry is performed before, one month and one year following POEM for evaluation of short- and long-term outcomes. Recently, high-resolution manometry with esophageal pressure topography has revolutionized the diagnosis and classification of achalasia and related motility disorders. ${ }^{48}$ Chicago $^{46}$ classification based on high-resolution manometry is extremely useful for precise diagnosis. Standard esophageal pull-through manometry is an alternative.

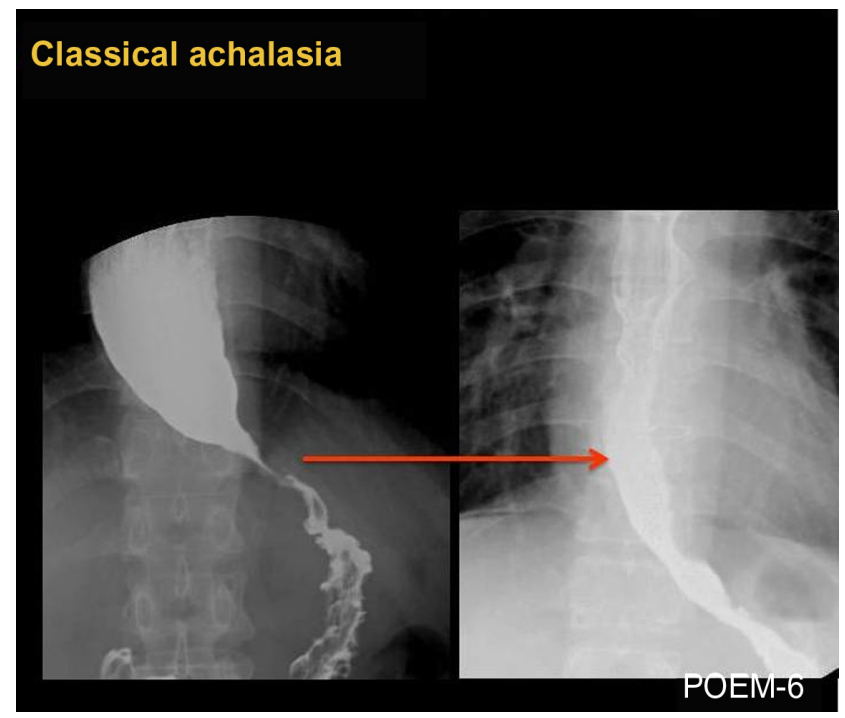

Figure 2 Barium esophagogram before (left) and after (right) POEM in a case of classical achalasia, showing obvious opening of EGJ and smooth passage of contrast after POEM. 


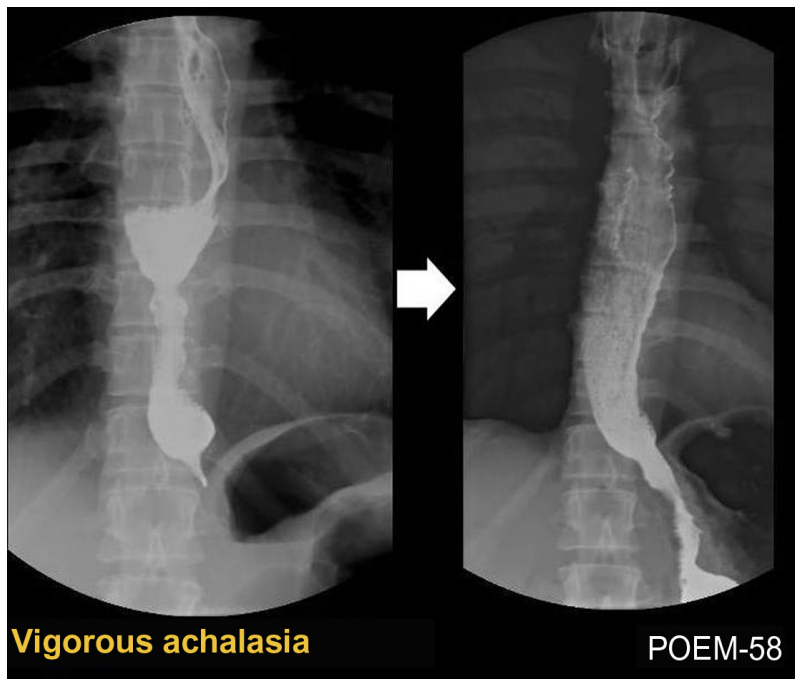

Figure 3 Barium esophagogram before (left) and after (right) peroral endoscopic myotomy (POEM) in a case of vigorous achalasia showing disappearance of the simultaneous body contractions, obvious opening of the esophagogastric junction and smooth passage of contrast after the POEM procedure.

\section{Laboratory examination}

Routine hematological, blood chemistry and coagulation tests as well as electrocardiography should be performed before POEM as preoperative preparation. Echocardiography and spirography should be performed upon indication, especially in the elderly.

\section{Equipment required for POEM}

Endoscopes and associated equipment

A standard forward-viewing diagnostic gastroscope is used for the POEM procedure. If available, a large working channel $(3.2 \mathrm{~mm})$ endoscope is useful for endoscopic clearance of esophageal contents before POEM.

A transparent distal small "tapered" cap (ST Hood; Fujifilm Corporation, Tokyo, Japan) (Figure 5A) should be attached and securely fixed at the tip of the endoscope. An oblique cap (MH-588; Olympus Medical Systems Corporation, Tokyo, Japan) can be used as an alternative (Figure 5B). The oblique cap is particularly necessary for clipping the esophageal opening. Note that MH-588 and ST Hoods are not commercially available in the USA.

An overtube is used for stabilization of the endoscope and easy access to the esophagus. All equipment, including the endoscope itself, should be sterilized using ethylene oxide gas.

\section{Carbon dioxide $\left(\mathrm{CO}_{2}\right)$ insufflator}

$\mathrm{CO}_{2}$ gas insufflation is a critical factor to achieve a safe POEM. $\mathrm{CO}_{2}$ delivery is provided with the aid of a $\mathrm{CO}_{2}$ insufflator

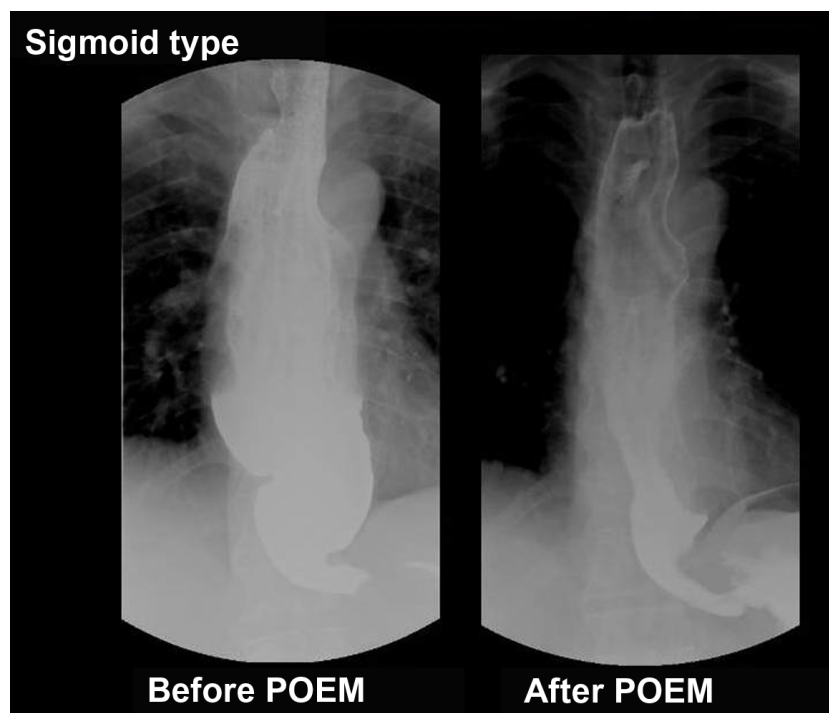

Figure 4 Barium esophagogram of sigmoid type of achalasia before and after perora endoscopic myotomy (POEM), showing significant reduction of esophageal dilatation and smooth passage of contrast from the esophagogastric junction.

(eg, a UCR; Olympus) and standard insufflating tube (such as an MAJ-1742; Olympus) (Figure 6A). Endoscopic $\mathrm{CO}_{2}$ insufflation with a controlled gas feed of $1.2 \mathrm{~L} / \mathrm{min}$ is beneficial for reducing the risk of both mediastinal emphysema and air embolization. The air/water button should be closed during POEM (Figure 6B).

\section{Knife}

A triangle-tip knife (TT knife ${ }^{49}$ ) (in this case a KD-640 L; Olympus) is used for submucosal dissection and circular myotomy (Figure 5C). Coagulating forceps (eg, Coagrasper, FD-411QR; Olympus) are used for hemostasis and coagulation of large vessels, when encountered during dissection.

\section{Electrogenerator}

A high-frequency electrosurgical energy generator (such as a VIO 300D; ERBE Elektromedizin GmbH, Tubingen, Germany) that has a spray coagulation mode with noncontact tissue dissection is preferred by the authors (Figure 6C). Spray coagulation (end cut mode, effect 2, $50 \mathrm{~W}$ ) is usually used for submucosal dissection and myotomy. Settings can be individually adjusted during the operation.

\section{Submucosal solution}

A glycerol mixture (10\% glycerol and 5\% fructose) or normal saline $0.9 \%$ with indigo carmine dye $(0.3 \%)$ is usually used for submucosal injection. Indigo carmine is important for blue staining of the submucosal space. 

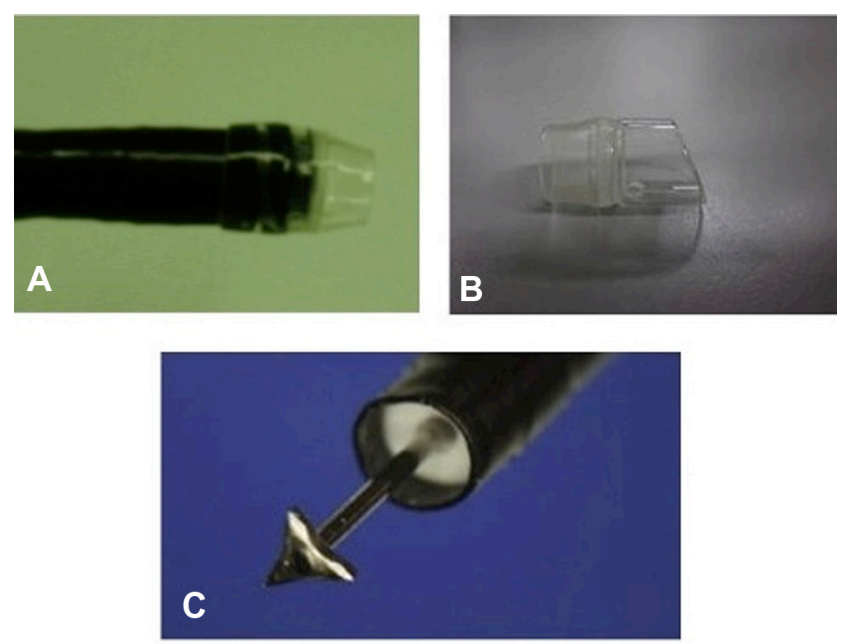

Figure 5 (A) A distal small transparent "tapered" cap, securely attached at the tip of the endoscope, is used during submucosal dissection and myotomy. (B) Alternatively, a transparent oblique cap can be used; this is necessary for clipping the esophageal opening. (C) Triangle-tip knife.

\section{Injection needle}

The initial injection is usually performed with a 25 gauge injection needle.

\section{Gentamycin flush}

At the end of myotomy and before closure of the mucosal entry, $80 \mathrm{mg}$ of gentamicin, diluted in $20 \mathrm{cc}$ of normal saline solution $(0.9 \%)$, should be flushed into the submucosal tunnel.

\section{Hemostatic clips}

For final closure of the mucosal entry site, hemostatic clips (eg, EZ-CLIP, HX-110QR; Olympus) are applied.

\section{Preparation for POEM procedure}

Patients should be placed on a clear liquid diet for 24 hours before the procedure. Sennoside ( 2 tablets, $12 \mathrm{mg}$ ) is taken with liquid at bedtime on the day before POEM to reduce GI motility during the procedure. The time of onset is 6 to 10 hours after ingestion.

Endoscopic clearance of esophageal contents before POEM is of significant importance. An empty esophagus avoids aspiration during induction of anesthesia and is important for clear endoscopic view during the procedure. Flushing with water containing a small amount of simethicone can also be done to eliminate gas and foamy mucus in the esophagus. Endoscopic clearance from residues is more difficult in sigmoid-type achalasia and should be performed on the day before POEM just before intubation to avoid aspiration. Patients are fasted on the day of POEM.

Prophylactic intravenous antibiotics are started during POEM and continued for at least three days in uncomplicated
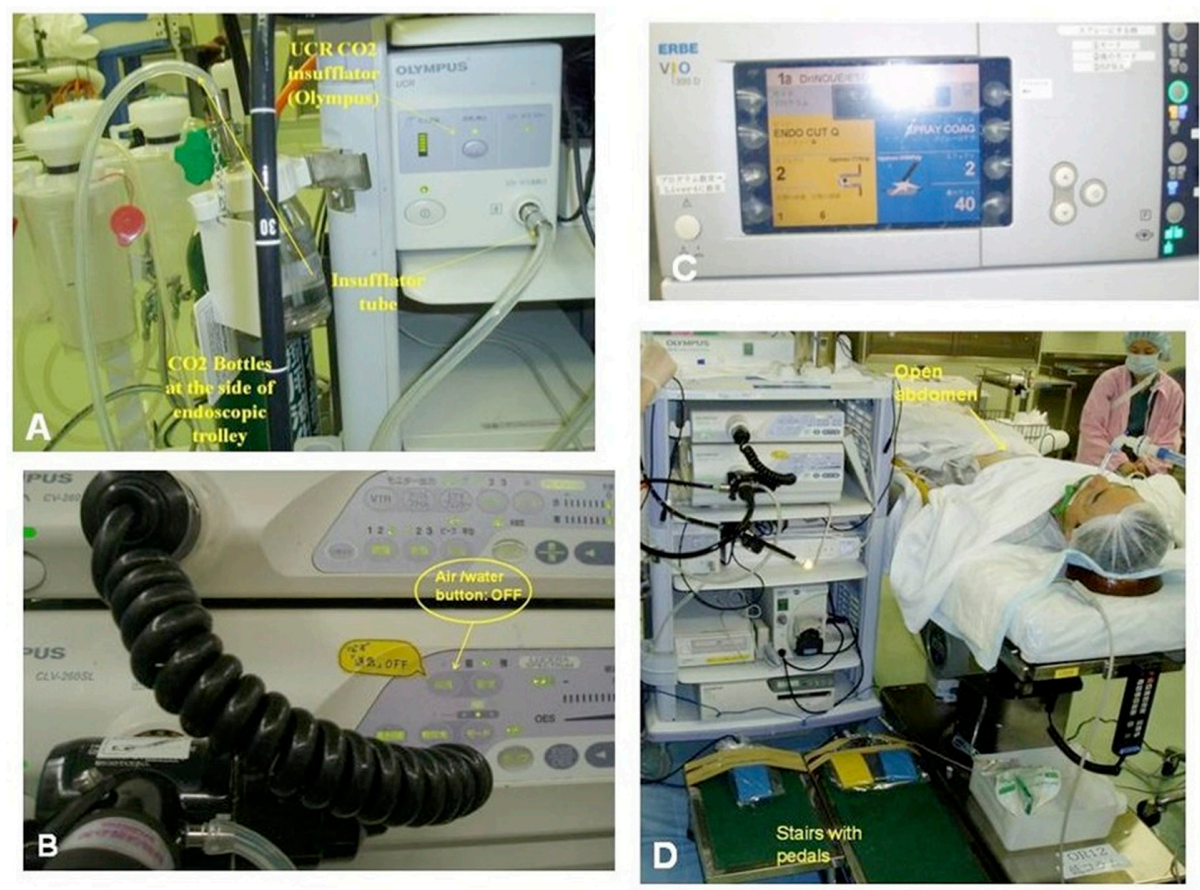

Figure 6 (A) The $\mathrm{CO}_{2}$ insufflator (UCR; Olympus Medical Systems Corporation, Tokyo, Japan) used with a regular insufflating tube (MAJ-I742; Olympus) to maintain CO, insufflation during endoscopy. (B) The air/water button of the endoscope should remain closed during peroral endoscopic myotomy. (C) High-frequency electrogenerator (VIO 300D; ERBE Elektromedizin GmbH, Tubingen, Germany). (D) The endoscopic trolley is shown situated at the right side of the intubated patient.

Notes: The patient is in a supine position, with open abdomen and periodically checked during the procedure. Cut and coagulation pedals are fixed on metallic stairs on the right side of the patient. 
cases. Usually, an intravenous infusion of cefazolin $1 \mathrm{~g}$ in $100 \mathrm{~mL}$ normal saline $0.9 \%$ over 30 minutes twice per day is administered. Then patients are transitioned to an additional four days of oral antibiotics.

\section{The POEM procedure}

Step I: intratracheal intubation and $\mathrm{CO}_{2}$ insufflation POEM is performed in the operation room under general anesthesia with intratracheal intubation, with the patient in the supine position.

As there is a potential risk of mediastinal emphysema or pneumoperitoneum, exclusive $\mathrm{CO}_{2}$ gas insufflation through the endoscope is mandatory not only to reduce the risk of these but also to reduce the risk of air embolization. It is important to repeatedly check the air/water button, which must remain closed during the entire procedure, while $\mathrm{CO}_{2}$ is insufflated. Positive pressure ventilation should be maintained at higher pressures than those generated by the endoscopist's exclusive $\mathrm{CO}_{2}$ insufflation. This setting seems to reduce the risk of mediastinal emphysema and pneumoperitoneum.

The patient's abdomen remains in open view during POEM (Figure 6D), so immediate diagnosis of severe pneumoperitoneum can be made. To prevent abdominal compartment syndrome, the upper abdomen is checked periodically during the procedure, while muscle relaxants are used. When the abdomen is excessively distended, drainage is performed using an injection needle.

\section{Step 2: creation of submucosal tunnel Mucosal entry}

After a $10 \mathrm{~mL}$ submucosal injection of the above-mentioned solution [either glycerol mixture (10\% glycerol and 5\% fructose) or normal saline $0.9 \%$ with indigo carmine dye $(0.3 \%)]$, a $2-\mathrm{cm}$ longitudinal incision is created at the 2 o'clock position using a TT knife, on the anterior esophageal wall approximately $13 \mathrm{~cm}$ proximal to the EGJ, just below the compression of the left main bronchus (Figure 7A). Anterior myotomy potentially avoids damage to the angle of His, located at the 8 o'clock position, which is a natural barrier to postoperative GERD. The estimated length of the submucosal tunnel, although individualized, becomes approximately $16 \mathrm{~cm}(29-45 \mathrm{~cm})$. If patients have abnormal contractions of the upper esophagus, a longer myotomy is required.

\section{Creating the submucosal tunnel}

The application of the endoscopic submucosal dissection $(\mathrm{ESD})^{49}$ technique to create the submucosal tunnel
(Figure 7B) was one of the most important steps in the development of POEM. In the submucosal tunnel technique, precise direct visual control combined with established ESD hemostatic techniques make the POEM procedure safe. ${ }^{50}$

A transparent distal cap is a useful tool for entering and maintaining endoscopic visualization within the submucosal space, managing bleeding and manipulating the instruments such as coagulation forceps, knife and injection needle. It is also useful for clipping the esophageal opening at the end of the procedure.

It is of great importance that the direction of the submucosal tunnel is perpendicular to the circular layer. Attention should be paid to not injuring the mucosal layer, as this is the only barrier between the mediastinum and esophageal lumen after myotomy. A critical view of safety is to keep the endoscope close to the circular muscle layer and away from the mucosa. The tunnel is passed over the EGJ and the gastric lumen is entered 2-3 cm distally (Figure 7B).

Repeated submucosal injection is necessary to keep a safe distance between mucosal flap and muscle layer. It is recommended the injection needle remain inside the plastic sheath to prevent damage to the muscular layer or to the mucosal flap during injection. The width of the tunnel is about one-third of the circumference of the esophagus.

Identification of palisade vessels within the submucosal space is helpful in identifying the location of the EGJ (Figure 7C). Once the tip of the endoscope has reached the cardia, the submucosal space will be opened widely.

The location of the distal tunnel margin can be verified using a retroflexion view from within the gastric lumen (Figure 7D). Large vessels within the submucosal tunnel are coagulated using hemostatic forceps in soft-coagulation mode.

\section{Identification of the EGJ}

The endoscopist should be able to identify the EGJ to complete the myotomy at the LES high-pressure area responsible for the achalasia. Some useful points to aid identification of the EGJ are: the insertion length of the endoscope, that the submucosal tunnel becomes narrow at the EGJ, palisade vessels are identified at the EGJ (Figure 10C), the submucosal space is abruptly widened and vessels increased obviously at the gastric side of the submucosal tunnel and compression by diaphragmatic crus.

A further useful indicator of the EGJ is a marked increase in resistance when the endoscope reaches the EGJ, followed by a prompt easing when it enters the gastric submucosal space. The endoscopist should be very careful not to damage 

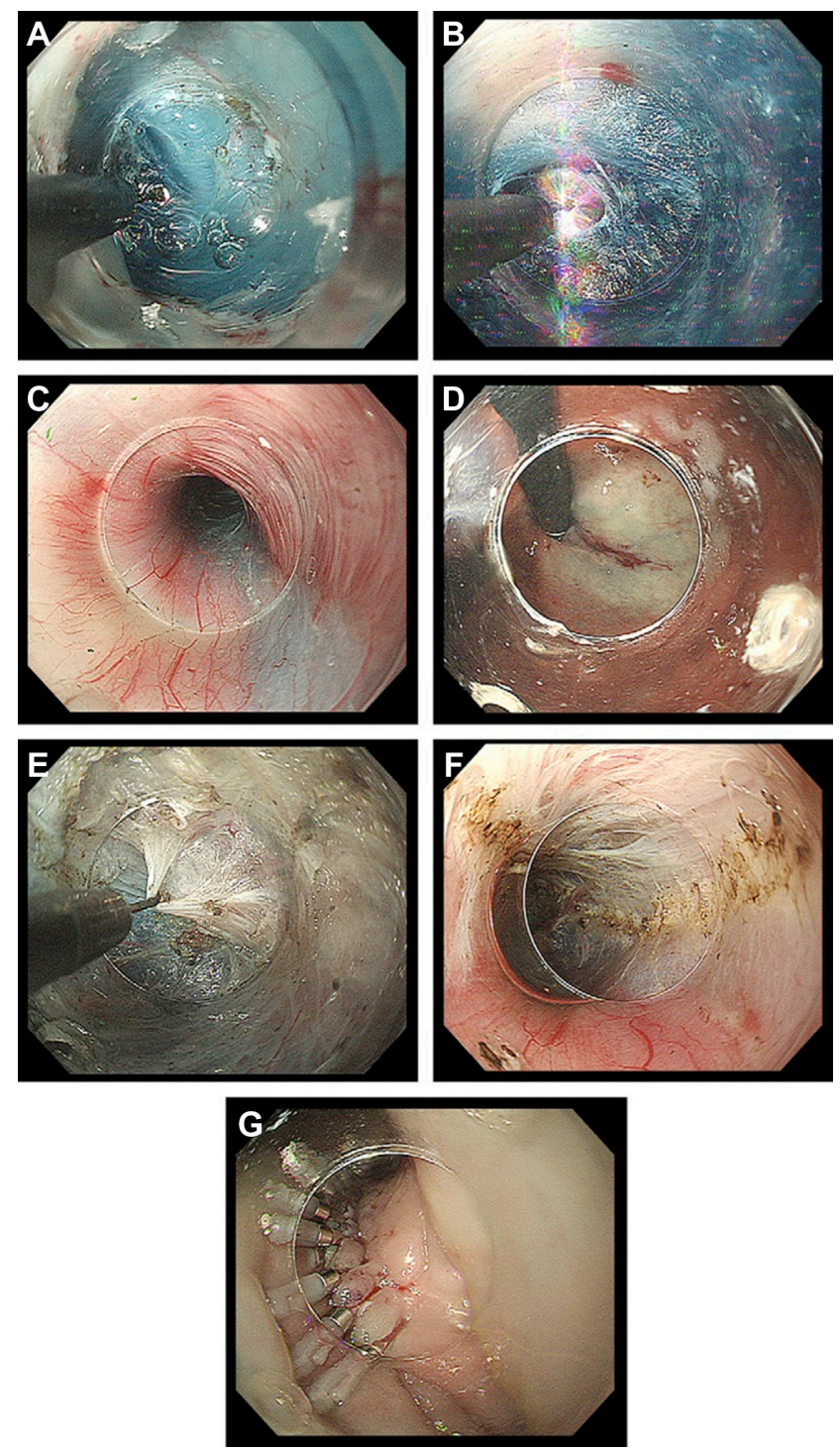

Figure 7 (A) Longitudinal incision at the 2 o'clock position. (B) Dissection plane. (C) Palisade vessels within the submucosal layer at the esophagogastric junction. (D) The distal margin of the tunnel verified using a retroflexion view from within the gastric lumen. (E) The sharp tip of a triangle-tip knife is used to catch circular muscle bundles and then retract and dissect them toward esophageal lumen. (F) Longitudinal muscle is identified at the bottom of myotomy site. (G) Closure with endoscopic clips.

any large vessel on the gastric side. In cases where anatomy is not clear, re-injection is useful to clearly identify the structures at this area.

\section{Step 3: endoscopic myotomy}

\section{Dissection of sphincter muscle}

Dissection of the circular muscle bundle should be started inside the submucosal tunnel, $2 \mathrm{~cm}$ distal to the mucosal entry point and more than $10 \mathrm{~cm}$ proximal to the EGJ (Figure 7E). A TT-knife permits selective dissection of the inner circular muscle layer. Use of this knife avoids serious damage to the longitudinal muscle layer, while all processes can be done with direct endoscopic visual control, which is mandatory for maintaining safety.

Because the thickness of the circular muscle cannot be predicted, it is advisable to initiate myotomy by careful stepby-step coagulation of the circular muscle bundles until the longitudinal muscle layer is identified.

Subsequently, the triangle base of the TT-knife should be safely touched to the longitudinal layer, permitting separation and selective dissection of circular muscle bundles. This circular muscle dissection method using a TT-knife can be described as the three-step myotomy technique (Figure 7E), in which the first step involves catching the circular muscle bundle, the second lifting the muscular bundle toward the submucosal lumen and the third dissecting the muscle by spray coagulation current (in endocut mode, 40-60 W, effect 2).

A plane of longitudinal muscle should be identified at the bottom of the myotomy site (Figure 7F). It is important to keep the thin longitudinal muscle layer as intact as possible to reduce the risk of injury to mediastinal structures.

Circular muscle dissection advances from proximal to distal, maintaining the correct dissection plane. The myotomy is extended for a distance of $2 \mathrm{~cm}$ to the stomach.

Myotomy at the narrow EGJ has a higher risk either of mucosal damage or laceration of the longitudinal muscle. Although defects in the longitudinal muscle layer, even small ones, may result in pneumoperitoneum or pneumomediastinum, they have no clinical significance when the mucosal flap remains intact. It is advisable to reduce $\mathrm{CO}_{2}$ insufflation at the EGJ to prevent severe pneumoperitoneum or pneumomediastinum. Smooth passage of the endoscope through the EGJ during POEM provides immediate confirmation of complete myotomy.

During circular myotomy, longitudinal muscle fibers may split from each other and the mediastinum might be observed. At the LES, particular attention should be paid to ensuring that all circular muscle bundles responsible for achalasia are cut.

\section{Avoiding GERD}

In laparoscopic myotomy, the natural antireflux mechanisms are impaired and a partial antireflux procedure, such as Dor fundoplication, is routinely performed to prevent postoperative GERD. In contrast after POEM no antireflux procedure is necessary, since the hiatal attachments and the acute angle of His are left untouched and the flap-valve mechanism intact. 


\section{Depth and length of endoscopic (POEM) myotomy Myotomy depth}

In contrast to surgical myotomy, in which full thickness myotomy is performed, selective circular myotomy is feasible in POEM. The circular muscle layer is the thickest muscle responsible for achalasia, while longitudinal muscle is naturally thin. In the authors' case series, the high LES pressure decreased to normal, without any incision of the longitudinal muscle layer. ${ }^{38-40}$

\section{Myotomy length}

A major advantage of POEM is the ability to control myotomy length. While in surgery a limited length with a maximum of $8 \mathrm{~cm}$ is generally performed, ${ }^{21}$ in POEM, myotomy is routinely more than $10 \mathrm{~cm}$ and may be as long as $25 \mathrm{~cm}$, as reported in the authors' case series. ${ }^{38,39,41}$

Moreover, in laparoscopic Heller (Dor) myotomy, the surrounding structures need to be dissected to expose the abdominal esophagus, which demands an additional antireflux procedure. In contrast, POEM permits any myotomy length required and in any direction, without injury to surrounding structures. In cases with vigorous achalasia (Figure 3) or diffuse esophageal spasm, longer myotomy is recommended. A standard long myotomy is $10-15 \mathrm{~cm}$ including at least $2 \mathrm{~cm}$ at the gastric side, while extended long myotomy is more than $15 \mathrm{~cm}$.

In failed surgical cases or after previous POEM failure, posterior POEM is performed to avoid previous surgical site scarring.

\section{Step 4: closure of mucosal entry}

Before closure of the mucosal entry, $20 \mathrm{~mL}$ of saline with $80 \mathrm{mg}$ gentamycin is sprayed into the submucosal tunnel. After completion of the myotomy, the EGJ is controlled for oozing, laceration, or perforation of esophageal mucosa, while LES relaxation is also evaluated by retroflex view of cardia (Figure 7D). The stomach should also be emptied from fluid and gas.

The mucosal entry site, which is usually $2-3 \mathrm{~cm}$ long, is closed with five to ten endoscopic clips (Figure 7G). The first clip should be placed at the distal end of the longitudinal opening to create a fold. This fold is used as a guide to place the other clips. The span between two clips should be about $5 \mathrm{~mm}$. Successful closure of mucosal entry can be confirmed by endoscopic appearance. Even when mucosal entry is elongated over the myotomy site, tight mucosal closure with clips avoids leakage of esophageal contents into the mediastinum.

\section{Postoperative care}

Laboratory examinations, thorax X-ray, gastroscopy and barium esophagogram are routinely performed the next day after procedure to exclude possible complications (perforation, leakage or inflammation) and to evaluate efficacy of myotomy. If no mucosal damage is found during endoscopy, a liquid meal is started and then gradually advanced as detailed described in the next paragraph; if a mucosal defect is present, the patient is fasted until confirmation of defect closure.

Moreover, adequate esophageal emptying and absence of leaking enables oral intake to resume. Patients begin by drinking liquid on postoperative Day 1 , then take soft food on postoperative Day 2 and can resume a normal diet on postoperative Day 3.

In uncomplicated cases, an intravenous infusion of antibiotics is delivered for 3 days following POEM, then patients are transitioned to an additional 4 days of oral antibiotics.

\section{Complications}

No severe clinically significant complications, such as mediastinitis, hemorrhage or mucosal necrosis, have been reported in more than 200 POEM procedures performed at the Digestive Disease Center of the Northern Yokohama Hospital $^{40}$ (unpublished data).

All complications were conservatively treated with prolongation of fasting and no other therapies were necessary. None of the patients had postoperative subcutaneous emphysema as judged on clinical grounds, but CT scan just after POEM, revealed minor pneumomediastinum in the majority of patients, without however, clinical significance. As soon as the mucosal flap is intact and the mucosal gap can be adequately closed at the end of the procedure, mild mediastinal emphysema during POEM had no clinical consequences. This phenomenon is similar to the pneumomediastinum seen following thoracoscopic surgery. ${ }^{51}$

Peritonitis developed in one patient, which was controlled conservatively by antibiotics and observation. Minor bleeding during dissection was seen in the majority of cases and was easily controlled by endoscopic coagulation. It is the same as minor bleeding during surgery.

Mucosal damage at the EGJ was experienced in three cases, which was treated conservatively with observation, prolonged fasting and longer intravenous antibiotic therapy. Multiple clips were placed in two of these patients. No further interventions were necessary. Achalasia-related symptoms improved in all patients in the long-term. 
During follow-up, symptomatic GERD was observed in $<20 \%$ of patients, which responded well to proton pump inhibitors.

\section{Training in POEM}

There are important ethical considerations regarding training in POEM, which is a novel procedure falling between NOTES and advanced endoscopic intervention. Neither gastroenterologists nor surgeons are usually absolutely familiar with this technically demanding procedure. While endoscopists are generally familiar with endoluminal procedures, surgeons are usually familiar with laparoscopic/thoracoscopic procedures. Surgeons can easily recognize the structures beyond the mucosa, while endoscopists are more experienced in handling the endoscope within the natural lumen.

POEM, however, is a procedure that requires both capabilities: good endoscope manipulation, recognition of luminal structures, and surgical knowledge of extraluminal structures, particularly vessels, nerves and mediastinal anatomy. Currently, POEM is performed only in clinical studies and restricted to specialized centers. However, the initial promising results and the increasing positive international experience have made the need for a training system in POEM procedure more urgent.

The basic requirements of an operator intending to perform POEM are shown in Table 3.

To close the training gap and prevent serious life-threatening complications, after careful observation of POEM performed by specialists, an animal model is first proposed in the present study for training in POEM, prior to undertaking the procedure in humans. Training should encompass set up of equipment, followed by training using an explant model, then training using a live pig.

\section{Non-survival porcine model}

The pig is the most appropriate animal model for training in POEM due to its anatomy being similar to that of humans. Pigs have a long esophagus, so are good models for practice. Additionally, the porcine esophagus has the advantage of easy mobilization due to the absence of tight junctions to surrounding organs, in contrast to the human esophagus, which is tightly connected to surrounding structures. As a consequence, the porcine esophagus can be removed as one with the stomach (Figure 8A).

Although there is no blood flow, the pig esophagus constitutes the cheapest and most reproducible non-survival organ model for practicing and training in POEM. The explant pig model is less expensive than the live pig model. Further, with an organ model, neither the entire animal nor anesthesia is necessary and the trainee does not need to be concerned about possible complications.

\section{Preparation of the pig organ model}

Fresh pig organs from a butcher are recommended. The esophagus and stomach should be prepared and checked for holes. Unnecessary tissue and fat around the organ should be trimmed but membrane and vessels outside the esophagus should remain if possible.

Preparation of the pig model is shown in Figures 9-12. First, the distal end of the gastric greater curvature is cut and the organ is cleaned with warm water. Then, any holes in the organ are fixed. Following this, 20-layer gauze is put into saline before being wrapped around the esophagus. Subsequently, the esophagus is put into a plastic case without twisting, while the proximal esophageal end should extend from a hole on one side of the case (Figures 10 and 11). The plastic case should then be placed on a water absorption sheet and the lids closed.

The greater gastric curvature and pylorus can then be closed with clamps and a neutral electrode be placed under the stomach. The stomach should then be covered with wet gauze dipped in saline (Figure 11). If the gauze is not wet, then the output for the cautery unit will not be stable. It is important to keep adding saline onto the model, especially the stomach, which remains in contact with the neutral electrode and the EGJ during the trial.

Three-prong grasping forceps are then placed at the opening of the proximal esophagus and an overtube is inserted without twisting the esophagus. Then, the organ model and overtube should be fixed to the table with belts (Figure 12).

\section{Performance and assessment of POEM on the pig organ model}

POEM should then be performed according to standard technique described for use in humans..$^{38,39,41}$ At the end of

Table 3 Basic requirements of those performing peroral endoscopic myotomy (POEM)

Familiarity with handling gastrointestinal endoscope Knowledge of anatomy of esophagus and esophagogastric junction Knowledge of pathophysiology of achalasia Knowledge of how to perform POEM procedure, including set up of device and patient care during perioperative period 
the procedure, blue dye, from submucosal injection, can be seen from the outside at the distal esophagus and EGJ (Figure 8A).

The trainee's skill can be assessed after practicing the procedure by confirming the length and completeness of circular myotomy by external opening of the esophagus (Figures 11B and C). Normal diverticulum should be identified at the gastric pig cardia after external longitudinal incision of distal esophagus and EGJ (Figure 8D).

\section{Disadvantages of the pig organ model}

A major disadvantage of this model, which also applies to all animal models, is that the normal porcine esophagus is different from a human achalasia-affected esophagus, which is usually thicker. A minor disadvantage is that the porcine esophageal submucosal space is softer and more easily dissected than in humans.

In this article the authors proposed a porcine model for training in POEM. If this model proved to be finally efficacious for training this is the question of further studies.

\section{Survival porcine model for training in POEM}

A $60 \mathrm{~kg}$ female pig under general anesthesia, with intratracheal intubation and without tracheotomy, in a supine position, is usually recommended. To ensure the esophagus
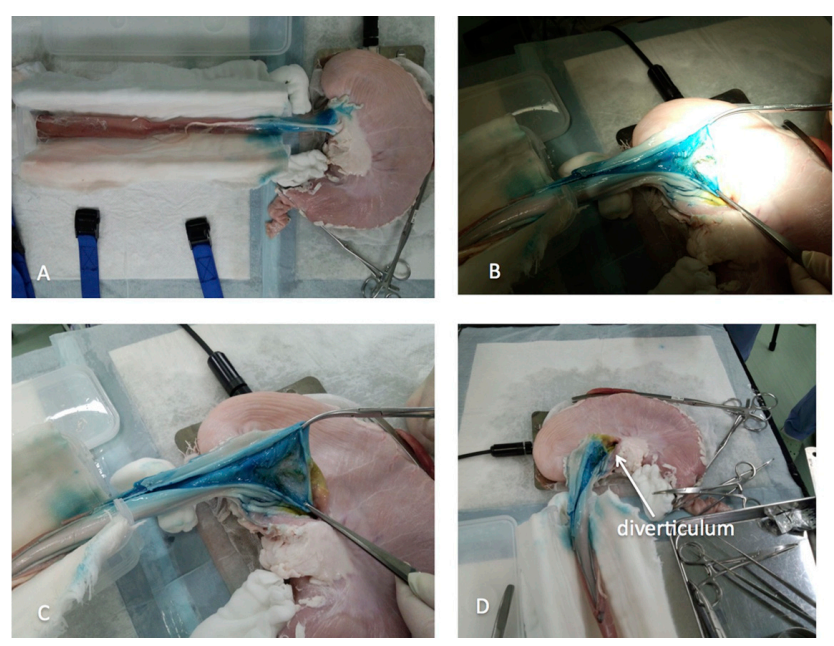

Figure 8 Non-survival organ model for training in peroral endoscopic myotomy (POEM). (A) Porcine esophagus and stomach are removed as one unit. POEM is performed following the same principles as in humans. At the end of the procedure, blue dye from the submucosal injection can be identified from the external side at the distal esophagus and esophagogastric junction. (B and $\mathbf{C}$ ) After completion of POEM, circular myotomy is controlled by external longitudinal incision of the distal esophagus and gastric cardia. (D) A normal diverticulum identified at the gastric cardia after external longitudinal incision.

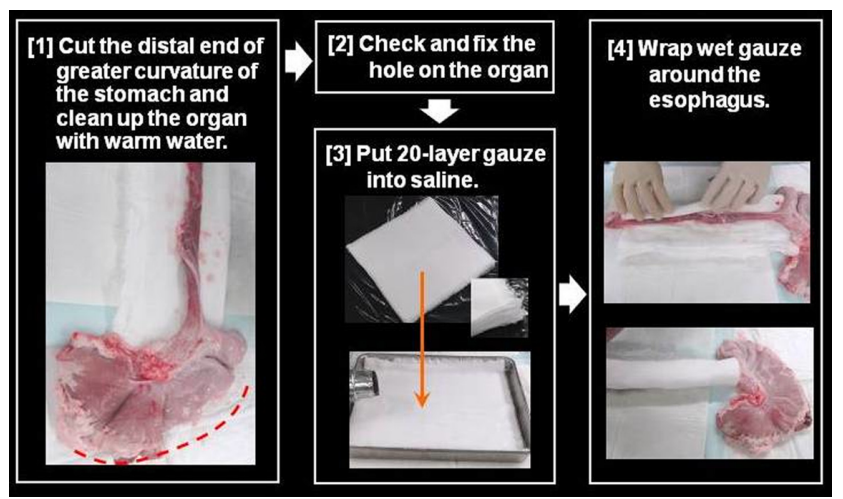

Figure 9 Preparing an organ model for training in peroral endoscopic myotomy. Notes: First, the distal end of gastric greater curvature is cut and the organ is cleaned with warm water. Following this, 20 -layer wet gauzes are placed below the stomach and wrapped around the esophagus.

and stomach are empty, 2 days fasting is recommended prior to the procedure. POEM is performed according to the same principles and with the same equipment as described for humans.

\section{International experience of POEM}

Inoue and colleagues performed POEM for the first time in humans on September 8, 2008.38,39,41 Since then, more than 200 consecutive patients with achalasia, aged from 3 to 87 years old, have been successfully treated with POEM at the Digestive Disease Center of Showa University, Northern Yokohama Hospital (unpublished data). These included 16 patients with sigmoid-type achalasia (Figure 4), eight patients with vigorous achalasia (Figure 3 ), one patient with severe diffuse esophageal spasm and five patients with previous surgical failure. Dysphagia was the predominant symptom in all patients, while chest pain was reported in $64 \%$ of cases. Abnormal contractions were closely related to chest pain.

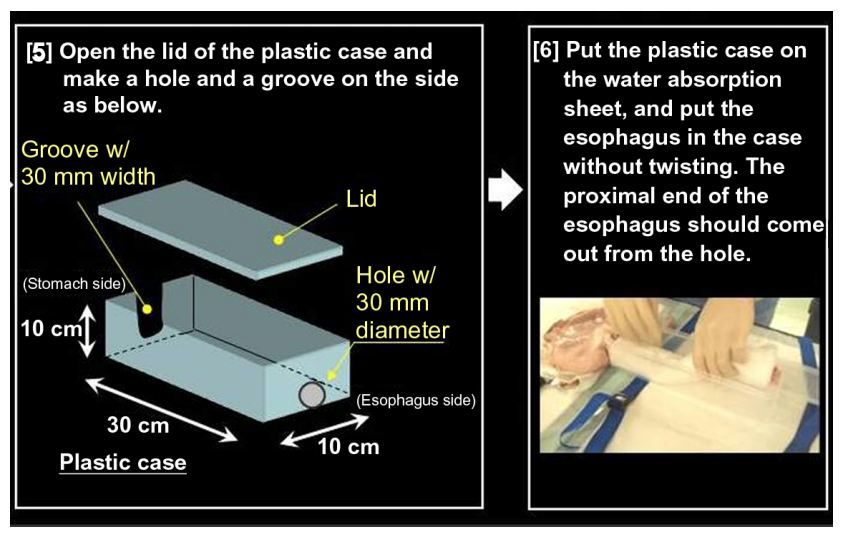

Figure 10 The organ model is put into a plastic case. 


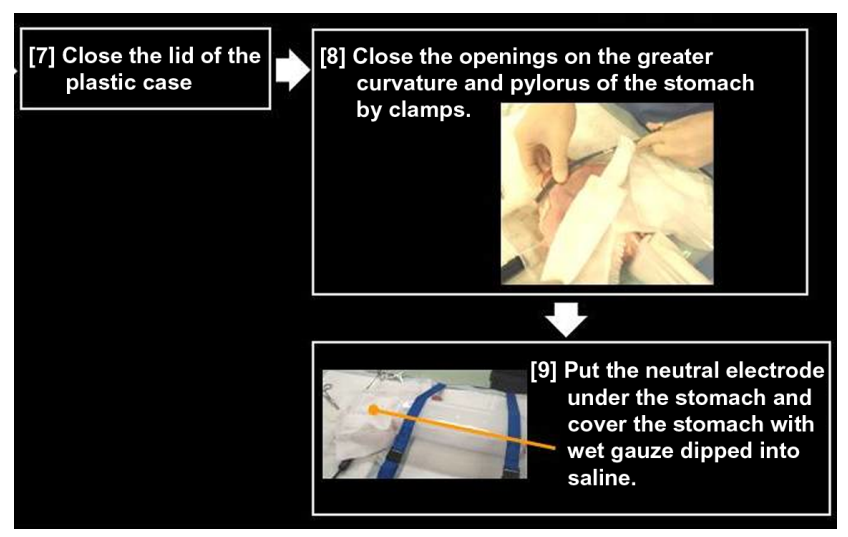

Figure I I Preparing the pig organ model.

Notes: Gastric greater curvature and pylorus are closed by clamps. The neutral electrode is placed under the stomach, which is covered with wet gauze dipped in saline.

All patients had symptom duration from 6 months to 50 years, with an average of 11 years. Operating time ranged from 56 to 240 minutes (average 113.4 minutes), while total mean myotomy length was $14 \mathrm{~cm}(3-23 \mathrm{~cm})$, with $11.1 \pm$ $3.4 \mathrm{~cm}$ at the esophageal side and $2.9 \pm 1.1 \mathrm{~cm}$ at the gastric side. Mean in-hospital stay was 5.9 days (range 3-10 days).

POEM was completed in all patients, including in a 3-year-old female. No patients died and all patients showed some improvement. The majority (99\%) showed dramatic improvement of both dysphagia and chest pain in the short-term. The mean Eckardt score improved from 6.36 before to 1.45 after POEM $(P=0.003$, Wilcoxon signed-rank test).

POEM was repeated in one patient with satisfactory results and pneumatic dilatation was necessary in another. No other patient received additional therapy for achalasia.

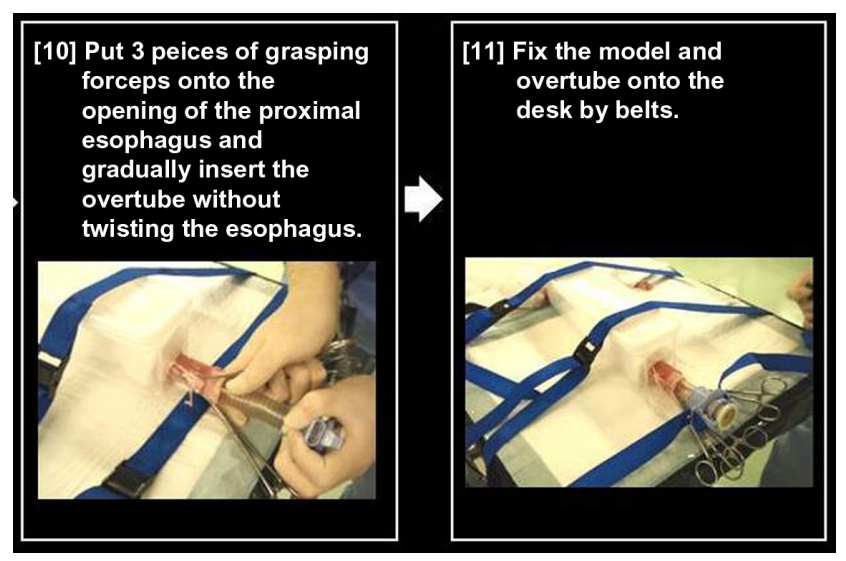

Figure 12 Preparing the pig organ model.

Notes: Three-prong grasping forceps are placed at the opening of the proximal esophagus and an overtube is gradually inserted without twisting the esophagus. Then, the organ model and overtube are fixed on the table with belts.
In all cases, follow-up endoscopy demonstrated only a small scar at the mucosal entry site. The LES resting pressure was reduced from $26.8 \pm 10.7 \mathrm{mmHg}$ to $12.6 \pm 4.5 \mathrm{mmHg}$ after POEM $(P<0.001$, paired Student's $t$-test $)$.

Based on this initial report, other centers worldwide began undertaking clinical studies of POEM for refractory achalasia or other esophageal motility disorders and reported satisfactory initial results concerning symptom relief and safety. ${ }^{52-54}$ The authors are aware of more than 100 cases of achalasia that have been successfully treated with POEM outside Japan (unpublished data, personal communications). These include 20 cases in Germany; two cases in Belgium; three cases in Switzerland; three cases in Italy; one case in Lebanon; and 20 cases in Oregon, six in San Diego, and 30 in New York in the USA.

Zhou et a ${ }^{53}$ reported on 42 achalasia patients successfully treated by POEM without complications. Mean myotomy length was $9.5 \mathrm{~cm}$ (range 7-13 cm). Dysphagia symptoms were significantly relieved in the long-term in all but one patient with a submucosal fistula, which was managed endoscopically (incision). Further, Swanström et al ${ }^{52}$ reported on five patients (mean age 64 years) with esophageal motility disorders treated with POEM. Operative time was 120-240 minutes, while median myotomy length was $7 \mathrm{~cm}$ (range 6-12 cm). Finally, in the first European prospective trial, POEM was successfully performed in 16 achalasia patients with a mean age of 45 years, achieving $>90 \%$ short-term symptom relief without serious complications. ${ }^{54}$

\section{Conclusion}

POEM is an effective, minimally invasive endoscopic treatment for esophageal achalasia, which is intended to become the gold standard for a permanent cure. POEM can be applied to any grade of achalasia and short-term results in humans are promising. Further long-term studies with a greater number of patients and from different centers are awaited. The porcine organ model, which is first described in this article, is an easy, inexpensive and reproducible animal model for training in POEM. It is particularly useful for aiding understanding of the main objective and all stages of the POEM procedure, without concern about complications and the success of myotomy can be assessed at the end of the procedure. This model has the potential to become a useful tool in closing the training gap between observation and human practice in POEM. However, further studies with a greater number of animals are necessary, to evaluate the efficacy of this training system. 


\section{Acknowledgment}

The authors would like to thank the Olympus Medical Systems Corporation, Japan, for providing the organ and animal models for POEM.

\section{Disclosure}

The authors declare no conflicts of interest in this work.

\section{References}

1. Spechler SJ. Clinical manifestations and diagnosis of achalasia. UpToDate ${ }^{\sqrt{R}}$ [web site on the Internet]. Waltham, MA: UpToDate, Inc; 2012 [updated Mar31, 2011]. Available from: http://www.uptodate.com/contents/clinicalmanifestations-and-diagnosis-of-achalasia. Accessed May 22, 2012.

2. Mikaeli J, Fazel A, Montazeri G, Yaghoobi M, Malekzadeh R. Randomized controlled trial comparing botulinum toxin injection to pneumatic dilatation for the treatment of achalasia. Aliment Pharmacol Ther. 2001;15(9):1389-1396.

3. Craft RO, Aguilar BE, Flahive C, et al. Outcomes of minimally invasive myotomy for the treatment of achalasia in the elderly. JSLS. 2010;14(3): 342-347.

4. Mikaeli J, Islami F, Malekzadeh R. Achalasia: a review of Western and Iranian experiences. World J Gastroenterol. 2009;15(40):5000-5009.

5. Japanese Society for Esophageal Diseases. Guidelines for the Clinical and Pathologic Studies on Carcinoma of the Esophagus. 9th ed. Tokyo: Kanehara; 1999.

6. Gockel HR, Schumacher J, Gockel I, Lang H, Haaf T, Nöthen MM. Achalasia: will genetic studies provide insights? Hum Genet. 2010; 128(4):353-364.

7. Campos GM, Vittinghoff E, Rabl C, et al. Endoscopic and surgical treatments for achalasia: a systematic review and meta-analysis. Ann Surg. 2009;249(1):45-57.

8. Richards WO, Torquati A, Holzman MD, et al. Heller myotomy versus Heller myotomy with Dor fundoplication for achalasia: a prospective randomized double-blind clinical trial. Ann Surg. 2004;240(3):405-412; discussion 412-415.

9. Ahmed A. Achalasia: what is the best treatment? Ann Afr Med. 2008;7(3):141-148.

10. Allescher HD, Storr M, Seige M, et al. Treatment of achalasia: botulinum toxin injection vs pneumatic balloon dilation. A prospective study with long-term follow-Up. Endoscopy. 2001;33(12):1007-1017.

11. Carter JT, Nguyen D, Roll GR, Ma SW, Way LW. Predictors of long-term outcome after laparoscopic esophagomyotomy and Dor fundoplication for achalasia. Arch Surg. 2011;146(9):1024-1028.

12. Eckardt AJ, Eckardt VF. Achalasia: Should pneumatic dilation be the primary treatment strategy? Nat Rev Gastroenterol Hepatol. 2010;7(4): 188-190.

13. Eckardt AJ, Eckardt VF. Treatment and surveillance strategies in achalasia: an update. Nat Rev Gastroenterol Hepatol. 2011;8(6):311-319.

14. Gockel I, Junginger T, Eckardt VF. Long-term results of conventional myotomy in patients with achalasia: a prospective 20-year analysis. J Gastrointest Surg. 2006;10(10):1400-1408.

15. Howard JM, Mongan AM, Manning BJ, et al. Outcomes in achalasia from a surgical unit where pneumatic dilatation is first-line therapy. Dis Esophagus. 2010;23(6):465-472.

16. Hughes MJ, Chowdhry MF, Walker WS. Can thoracoscopic Heller's myotomy give equivalent results to the more usual laparoscopic Heller's myotomy in the treatment of achalasia? Interact Cardiovasc Thorac Surg. 2011;13(1):77-81.

17. Kashiwagi H, Omura N. Surgical treatment for achalasia: when should it be performed, and for which patients? Gen Thorac Cardiovasc Surg. 2011;59(6):389-398.

18. Francis DL, Katzka DA. Achalasia: update on the disease and its treatment. Gastroenterology. 2010;139(2):369-374.
19. Ortega JA, Madureri V, Perez L. Endoscopic myotomy in the treatment of achalasia. Gastrointest Endosc. 1980;26(1):8-10.

20. Lake JM, Wong RK. Review article: the management of achalasia a comparison of different treatment modalities. Aliment Pharmacol Ther. 2006;24(6):909-918.

21. Woltman TA, Pellegrini CA, Oelschlager BK. Achalasia. Surg Clin North Am. 2005;85(3):483-493.

22. Spiess AE, Kahrilas PJ. Treating achalasia: from whalebone to laparoscope. JAMA. 1998;280(7):638-642.

23. Pehlivanov N, Pasricha PJ. Achalasia: botox, dilatation or laparoscopic surgery in 2006. Neurogastroenterol Motil. 2006;18(9):799-804.

24. Kroupa R, Hep A, Dolina J, et al. Combined treatment of achalasia botulinum toxin injection followed by pneumatic dilatation: long-term results. Dis Esophagus. 2010;23(2):100-105.

25. Gorecki PJ, Hinder RA, Libbey JS, BammerT, Floch N. Redo laparoscopic surgery for achalasia. Surg Endosc. 2002;16(5):772-776.

26. Parise P, Santi S, Solito B, Pallabazzer G, Rossi M. Laparoscopic Heller myotomy plus Dor fundoplication in 137 achalasic patients: results on symptoms relief and successful outcome predictors. Updates Surg. 2011;63(1):11-15.

27. Salvador R, Costantini M, Zaninotto G, et al. The preoperative manometric pattern predicts the outcome of surgical treatment for esophageal achalasia. J Gastrointest Surg. 2010;14(11): 1635-1645.

28. Ellis FH Jr, Watkins E Jr, Gibb SP, Heatley GJ. Ten to 20-year clinical results after short esophagomyotomy without an antireflux procedure (modified Heller operation) for esophageal achalasia. Eur $J$ Cardiothorac Surg. 1992;6(2):86-89; discussion 90.

29. Mercer CD, Hill LD. Reoperation after failed esophagomyotomy for achalasia. Can J Surg. 1986;29(3):177-180.

30. Cowgill SM, Villalodid D, Al-Saadi S, Hedgecock J, Rosemurgy AS Postmyotomy recollection of premyotomy symptoms of achalasia is very accurate, supporting longitudinal studies of symptom improvement. Surg Endosc. 2007;21(12):2183-2186.

31. Kalloo AN, Singh VK, Jagannath SB, et al. Flexible transgastric peritoneoscopy: a novel approach to diagnostic and therapeutic interventions in the peritoneal cavity. Gastrointest Endosc. 2004;60(1): 114-117.

32. Zorrón R, Filgueiras M, Maggioni LC, Pombo L, Lopes Carvalho G, Lacerda Oliveira A. NOTES. Transvaginal cholecystectomy: report of the first case. Surg Innov. 2007;14(4):279-283.

33. Marescaux J, Dallemagne B, Perretta S, WattiezA, Mutter D, Coumaros D. Surgery without scars: report of transluminal cholecystectomy in a human being. Arch Surg. 2007;142(9):823-826; discussion 826-827.

34. Inoue $H$, Minami $H$, Satodate $H$, Kudo SE. First clinical experience of submucosal endoscopic myotomy for esophageal achalasia with no skin incision. Gastrointest Endosc. 2009;69(5):AB122.

35. Pasricha PJ, Hawari R, Ahmed I, et al. Submucosal endoscopic esophageal myotomy: a novel experimental approach for the treatment of achalasia. Endoscopy. 2007;39(9):761-764.

36. Sumiyama K, Gostout CJ, Rajan E, Bakken TA, Knipschield MA, Marler RJ. Submucosal endoscopy with mucosal flap safety valve. Gastrointest Endosc. 2007;65(4):688-694.

37. Perretta S, Dallemagne B, Donatelli G, Diemunsch P, Marescaux J. Transoral endoscopic esophageal myotomy based on esophageal function testing in a survival porcine model. Gastrointest Endosc. 2011;73(1):111-116.

38. Inoue $\mathrm{H}$, Tianle KM, Ikeda $\mathrm{H}$, et al. Peroral endoscopic myotomy for esophageal achalasia: technique, indication, and outcomes. Thorac Surg Clin. 2011;21(4):519-525.

39. Inoue H, Kudo SE. Per-oral endoscopic myotomy (POEM) for 43 consecutive cases of esophageal achalasia. Nihon Rinsho. 2010;68(9): 1749-1752. Japanese.

40. Inoue $\mathrm{H}$, Minami H, Kobayashi $\mathrm{Y}$, et al. Peroral endoscopic myotomy (POEM) for esophageal achalasia. Endoscopy. 2010;42(4):265-271.

41. Chiu P. Inoue H, Teoh AYB, et al. Per-oral endoscopic myotomy for treatment of hypertensive lower esophageal sphincter. Gastrointest Endosc. 2011;73:AB107. 
42. Eckardt VF. Clinical presentations and complications of achalasia. Gastrointest Endosc Clin N Am. 2001;11(2):281-292, vi.

43. Vaezi MF, Baker ME, Achkar E, Richter JE. Timed barium oesophagram: better predictor of long term success after pneumatic dilation in achalasia than symptom assessment. Gut. 2002;50(6):765-770.

44. Eckardt VF, Gockel I, Bernhard G. Pneumatic dilation for achalasia: late results of a prospective follow up investigation. Gut. 2004;53(5): 629-633.

45. Omura N, Kashiwagi H, Ishibashi Y, et al. Laparoscopic Heller myotomy and Dor fundoplication for the treatment of achalasia. Assessment in relation to morphologic type. Surg Endosc, 2006;20:210-213.

46. Kahrilas PJ, Ghosh SK, Pandolfino JE. Esophageal motility disorders in terms of pressure topography: the Chicago Classification. J Clin Gastroenterol. 2008;42(5):627-635.

47. Kahrilas PJ, Pandolfino JE. Esophageal neuromascular function and motility disorders. In: Feldman M, Friedman LS, Brandt LJ, editors. Sleisenger and Fordtran's Gastrointestinal and Liver Disease: Pathophysiology, Diagnosis, Management. Vol 1.9th ed. Philadelphia, PA: Elsevier; 2010:680-682.

48. Pandolfino JE, Roman S. High-resolution manometry: an atlas of esophageal motility disorders and findings of GERD using esophageal pressure topography. Thorac Surg Clin. 2011;21(4):465-475.
49. Inoue H, Minami H, Kaga M, Sato Y, Kudo SE. Endoscopic mucosal resection and endoscopic submucosal dissection for esophageal dysplasia and carcinoma. Gastrointest Endosc Clin N Am. 2010;20(1):25-34, v-vi.

50. Vantrappen G, Janssens J. To dilate or to operate? That is the question. Gut. 1983;24(11):1013-1019.

51. Tamiya Y, Nakahara K, Kominato K, et al. Pneumomediastinum is a frequent but minor complication during esophageal endoscopic submucosal dissection. Endoscopy. 2010;42(1):8-14.

52. Swanström LL, Rieder E, Dunst CM. A stepwise approach and early clinical experience in peroral endoscopic myotomy for the treatment of achalasia and esophageal motility disorders. J Am Coll Surg. 2011; 213(6):751-756.

53. Zhou PH, Cai MY, Yao LQ, et al. Peroral endoscopic myotomy for esophageal achalasia: report of 42 cases. Zhonghua Wei Chang Wai Ke Za Zhi. 2011;14(9):705-708. Chinese.

54. von Renteln D, Inoue H, Minami H, et al. Peroral endoscopic myotomy for the treatment of achalasia: a prospective single center study. $\mathrm{Am} \mathrm{J}$ Gastroenterol. 2012;107(3):411-417.
Therapeutics and Clinical Risk Management

\section{Publish your work in this journal}

Therapeutics and Clinical Risk Management is an international, peerreviewed journal of clinical therapeutics and risk management, focusing on concise rapid reporting of clinical studies in all therapeutic areas, outcomes, safety, and programs for the effective, safe, and sustained use of medicines. This journal is indexed on PubMed Central, CAS,

\section{Dovepress}

EMBase, Scopus and the Elsevier Bibliographic databases. The manuscript management system is completely online and includes a very quick and fair peer-review system, which is all easy to use. Visit $\mathrm{http}: / /$ www.dovepress.com/testimonials.php to read real quotes from published authors. 